\title{
A retrospective comparison of endoscopic stenting alone with stenting and radiotherapy in non-resectable cholangiocarcinoma
}

\author{
T E Bowling, S M Galbraith, A R W Hatfield, J Solano, M F Spittle
}

Departments of Gastroenterology T E Bowling A R W Hatfield

and Oncology, The Middlesex Hospital,

University College

London Hospitals

NHS Trust,

London

S M Galbraith

J Solano

M F Spittle

Correspondence to

Dr A R W Hatfield,

Department of

The Middlesex Hospital,

The University College

London Hospitals

London Hospit

NHS Trust,

London W1N 8AA.

22 July 1996

\begin{abstract}
Background and Aims-Radiotherapy has been reported to be of benefit in prolonging the survival of patients with cholangiocarcinoma. This study examined whether radiotherapy in addition to endo-
\end{abstract} scopic stenting improved survival.

Subjects-56 patients with obstructive jaundice due to histologically confirmed non-resectable cholangiocarcinoma.

Methods-A retrospective analysis of these patients who were treated either with endoscopic biliary stenting followed by external beam radiotherapy and internal iridium-192 brachytherapy $(n=28)$ or with stenting alone (control group; $n=28$ ). Results-The two groups were well matched in age, sex, and stricture type. Eighteen patients had a type I stricture (control group: 11; radiotherapy group: 7) at the time of diagnosis and 38 had a type II or III stricture (control group: 17; radiotherapy group: 21). The median (range) overall survival from diagnosis was seven (1-29) and 10 (4-75) months in the control and radiotherapy groups respectively: This difference did not reach statistical significance $(p=0 \cdot 06)$, but survival plots indicated a survival advantage in the radiotherapy group in the first nine months after diagnosis. Approximately one third survived longer than one year in both groups. More patients in the radiotherapy group required a stent change $(1.9 v 0.9: p=0.05)$, and also had a longer overall inpatient stay (42 days $v$ 19: $p<0 \cdot 001$ ). When examined on the basis of stricture type, there was a survival advantage in the first 10 months after diagnosis in those with a type II/III stricture (seven and 11 months in the radiotherapy and control groups respectively: $0 \cdot 01<$ p $<0 \cdot 05$ ). There was no difference in survival between the groups in those with a type I stricture. Numbers surviving longer than one year, stent survival, and number of stent changes were all similar between the two groups when examined on the basis of stricture type, but length of hospital stay remained considerably longer in all patients receiving radiotherapy.

Conclusion-The survival advantage of radiotherapy in those with a type II/III stricture is seen only in the first 10 months after diagnosis. The costs of radiotherapy and significantly increased time spent in hospital, however, raise doubts over its routine use in the management of nonresectable cholangiocarcinoma (Gut 1996; 39: 852-855)

Keywords: cholangiocarcinoma, retrospective analysis, stenting, radiotherapy, survival.

Cholangiocarcinoma is a relatively slow growing tumour that rarely metastasises, but nevertheless has a high mortality. ${ }^{1}$ Surgical resection is possible in only a small proportion of patients ${ }^{2-6}$ and, untreated, the mean survival rate is less than three months. ${ }^{7}$ Palliative approaches, such as endoscopic biliary drainage, improve the outlook with mean survival times varying between three and 12 months, although in most series there are a very small proportion of patients who survive for several years. ${ }^{4-12}$

Recent studies have suggested that cholangiocarcinoma is responsive to radiotherapy, and a variety of methods have been evaluated, including external beam radiotherapy, ${ }^{9}{ }^{13-18}$ intraoperative radiotherapy, ${ }^{19-21}$ internal radiotherapy ${ }^{22-33}$ and the combination of external and internal radiotherapy. ${ }^{30}{ }^{34-37}$ Combinations of internal biliary drainage with either internal radiotherapy using iridium-192 alone 22 $25-29^{2}$ or with external beam followed by internal iridium-192 radiotherapy ${ }^{30}{ }^{34-36}$ have also been examined. However, none of these studies were randomised or controlled and they involved only small numbers of patients. There have not, however, been any prospective controlled trials of radiotherapy and it is therefore difficult to assess, on the basis of current evidence, the true benefit of radiotherapy in the management of cholangiocarcinoma. We present a retrospective study of the outcome of patients with cholangiocarcinoma who either received internal and external beam radiotherapy plus endoscopic biliary drainage or who were stented alone.

\section{Methods}

Between 1988-1994 142 patients were referred to The Middlesex Hospital with suspected cholangiocarcinoma and were stented at endoscopic retrograde cholangiopancreatography for malignant biliary strictures. In 56 of these patients a histological diagnosis of cholangiocarcinoma was obtained either by biopsy or endoluminal brush cytology. None of these patients had resectable disease on the basis of 
TABLE I Details of all study patients

\begin{tabular}{llll}
\hline & $\begin{array}{l}\text { Control } \\
(n=28)\end{array}$ & $\begin{array}{l}\text { Radiotherapy } \\
(n=28)\end{array}$ & $p$ Value \\
\hline Male:female & $15: 13$ & $19: 9$ & NS \\
Age (median; range) & $65 \cdot 5(46-88)$ & $60 \cdot 5(35-78)$ & NS \\
Stricture type at diagnosis: I & 11 & 7 & NS \\
& 3 & 6 & NS \\
Survival: months (median; range) & 14 & 15 & NS \\
Patients surviving >1 year & $7 \cdot 0(1-29)$ & $10(4-75)$ & NS \\
Stent survival: months (median; range) & $10(36 \%)$ & $11(39 \%)$ & NS \\
Stent changes per patient & $5 \cdot 0(1-21)$ & $5 \cdot 0(1-26)$ & NS \\
Hospital stay: days (median; range) & $0 \cdot 9$ & $1 \cdot 9$ & p=0.05 \\
Patients with gastric outflow obstruction & $19(3-85)$ & $42(3-140)$ & p $<0.001$ \\
& 2 & 4 & NS \\
\hline
\end{tabular}

ultrasound or computed tomographic evidence, but they were all young and/or fit enough to make the consideration of radical radiotherapy worthwhile.

After initial endoscopic stent insertion 28 of these 56 patients received a combination of external beam radiotherapy $(30 \mathrm{~Gy}$ in 10 fractions) followed by brachytherapy ( $60 \mathrm{~Gy}$ ) using an iridium-192 wire placed inside the stent as previously described. ${ }^{22}$ In the

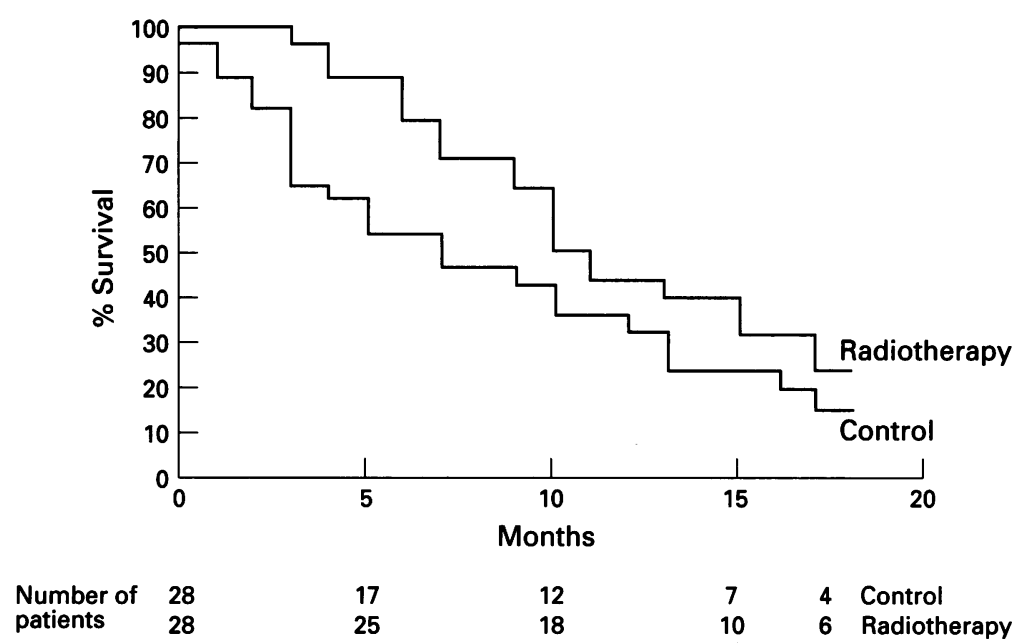

Figure 1: Kaplan-Meier survival curve for all patients treated with endoscopic stenting alone $(n=28)$. Actuarial survival from time of diagnosis between the two groups at six months: $p<0.01 ; 12$ months: $p>0 \cdot 1 ; 18$ months: $p>0 \cdot 1$.

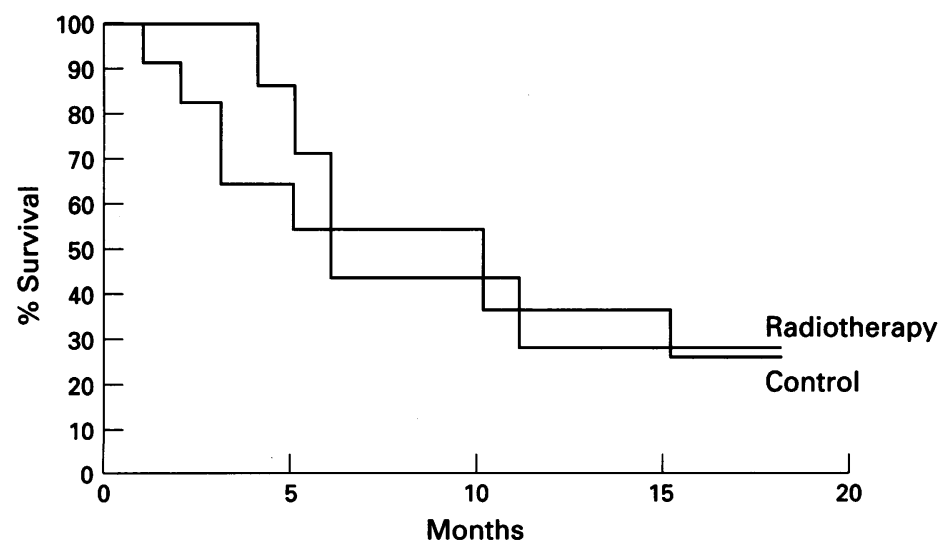

$\begin{array}{lclllll}\text { Number of } & 11 & 7 & 6 & 4 & 3 & \text { Control } \\ \text { patients } & 7 & 6 & 3 & 2 & 2 & \text { Radiotherapy }\end{array}$

Figure 2: Kaplan-Meier survival curve for patients with a type I stricture treated with endoscopic stenting alone $(n=11)$ or with radiotherapy and stenting $(n=7)$. Actuarial survival from time of diagnosis between the two groups at six months: $p>0 \cdot 1 ; 12$ months: $p>0 \cdot 1 ; 18$ months: $p>0 \cdot 1$. remaining 28 patients radiotherapy was also recommended to the referring clinicians in more geographically distant health districts, but never pursued. This group was therefore available for comparison as a 'stenting only' control group.

The end points of the study were either death or continuing survival on 1 July 1995. All patients examined were diagnosed before 1 July 1994, and therefore had had a minimum of 12 months follow up.

The primary comparison was length of survival from the time of diagnosis between the two groups. Other parameters looked at were length of hospital stay, number of stent changes per patient, length of stent survival (that is, time to stent blockage), and number of patients surviving longer than 12 months. In addition to whole group comparison, these various parameters were also examined on the basis of whether there was a type I stricture or a type II or III stricture at the time of diagnosis.

\section{Statistical methods}

The primary analysis of survival between the two groups was carried out by survival curves drawn up using the Kaplan-Meier method and analysed with the log rank test. The MannWhitney $U$ test was used for the secondary analyses including length of hospital stay and duration of stent survival.

\section{Results}

The two groups were well matched with similar sex and age distribution and stricture type (Table I). Taking the two groups as a whole three patients (two control, one radiotherapy) were still alive on 1 July 1995 with a follow up ranging from 12 to 22 months. Of those who died median survival was similar in the two groups and there was no difference in overall survival (Table I), however when examining the survival plot there is a survival advantage in the radiotherapy group in the first nine months after diagnosis (Fig 1). The numbers surviving for longer than 12 months and the length of stent survival were both similar between the two groups. More patients in the radiotherapy group required a stent change in the course of their illness $(1.9 v 0.9: \mathrm{p}=0.05)$, and there was a highly significant difference in the number of days spent in hospital (42 $v$ 19: $p<0.001$ ). Six patients in total (two control, four radiotherapy) required a gastrojejunostomy for gastric outflow obstruction.

When the results are examined on the basis of stricture type, the median survival of the two groups in those with a type I stricture is similar (Fig 2), but those with a type II or II stricture show an advantage in the radiotherapy group (seven $v 11$ months; $0.01<\mathrm{p}<0.05$ ) for the 10 months after diagnosis (Fig 3 ). The length of hospital stay remains significantly less in the control group irrespective of stricture distribution and stent survival and number of stent changes are similar between the two groups in all stricture types (Tables II and III). 


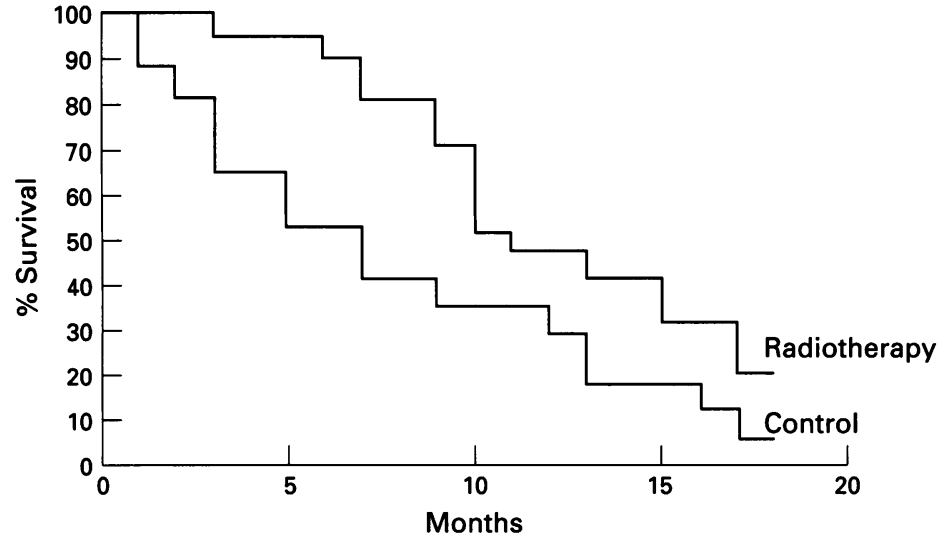

Number of 17

patients 21

11

6

15
1 Control

4 Radiotherapy

Figure 3: Kaplan-Meier survival curve for patients with a type II or III stricture treated with endoscopic stenting alone ( $n=17)$ or with radiotherapy and stenting $(n=21)$. Actuarial survival from time of diagnosis between the two groups at six months: $p<0.01 ; 12$ months: $p>0 \cdot 1 ; 18$ months: $p>0 \cdot 1$.

TABLE II Type I stricture

\begin{tabular}{llll}
\hline & $\begin{array}{l}\text { Control } \\
(n=11)\end{array}$ & $\begin{array}{l}\text { Radiotherapy } \\
(n=7)\end{array}$ & $p$ Value \\
\hline Age (median; range) & $65(46-88)$ & $66(58-76)$ & NS \\
Survival: months (median; range) & $4(1-29)$ & $6(5-75)$ & NS \\
Patients surviving >1 year & $4(36 \%)$ & $2(29 \%)$ & NS \\
Stent survival: months (median; range) & $5 \cdot 0(1-21)$ & $5 \cdot 0(1-26)$ & NS \\
Stent changes per patient & $0 \cdot 4$ & $0 \cdot 75$ & NS \\
Hospital stay: days (median; range) & $11(3-26)$ & $50(23-77)$ & p $>0 \cdot 001$ \\
\hline
\end{tabular}

TABLE III Type II/III stricture

\begin{tabular}{llll}
\hline & $\begin{array}{l}\text { Control } \\
(n=17)\end{array}$ & $\begin{array}{l}\text { Radiotherapy } \\
(n=21)\end{array}$ & $p$ Value \\
\hline Age (median; range) & $66(45-85)$ & $59(35-77)$ & NS \\
Survival: months (median; range) & $7 \cdot 0(2-29)$ & $11(4-43)$ & $0 \cdot 01<\mathrm{p}<0.05$ \\
Patients surviving >1 year & $6(35 \%)$ & $9(43 \%)$ & $\mathrm{NS}$ \\
Stent survival: months (median; range) & $4 \cdot 0(1-14)$ & $5 \cdot 0(1-17)$ & $\mathrm{NS}$ \\
Stent changes per patient & $1 \cdot 25$ & $2 \cdot 1$ & $\mathrm{NS}$ \\
Hospital stay: days (median; range) & $19(3-85)$ & $36(3-140)$ & $\mathrm{p}<0.05$ \\
\hline
\end{tabular}

\section{Discussion}

The use of radiotherapy in the management of cholangiocarcinoma was first advocated in 1981 , and since then there have been mixed results of its efficacy. Fletcher et al first described the combination of internal biliary drainage with internal radiotherapy using an iridium-192 wire inserted percutaneously. ${ }^{29}$ In the 18 patients studied the median survival was 11 months and they concluded that this form of therapy may be beneficial in the management of cholangiocarcinoma. Since this study several centres have also looked at this same combination with biliary drainage achieved either percutaneously or endoscopically, and they have all demonstrated a favourable response with mean survival times increased up to 16 months. ${ }^{22}{ }^{25-30}$ However, these studies were all small, not randomised and, most importantly, uncontrolled. Unfortunately there has been no prospective randomised controlled evaluation of radiotherapy in the management of cholangiocarcinoma.

In our study we used both internal and external beam radiotherapy. The iridium-192 wire causes an intense but localised radiation field resulting in minimal damage to sur-

rounding organs. The combination of this with the external beam radiotherapy provides a more uniform radiation field, especially in bulky tumours that may not be completely reached by the internal radiation alone. ${ }^{13} 30$

Although our study is retrospective, the number of patients with histologically confirmed disease who were eligible for consideration of radiotherapy is much greater than in any previous study, and it also has a well matched concurrent control group. All the patients in this study were initially selected for 'active treatment' with post-stenting radiotherapy as they represented, on clinical assessment, the better end of the patient spectrum. Over the period of this study there were 86 further patients stented for suspected cholangiocarcinoma who, because of their age and/or overall condition made any consideration of further treatment with radiotherapy unrealistic. The survival of this group of patients varied between three to 12 months.

It had proved impossible to carry out a prospective randomised trial comparing the two treatment groups as patient expectation of 'active' treatment led them to decline allocation to the stenting alone group. Many patients, however, lived long distances from our centre and although radiotherapy was recommended to their local clinicians it was often not pursued. It was this group of patients that we have used as our control group. The 56 patients in this study had similar demographic and survival data to other studies indicating that this was a representative and comparable sample of patients with cholangiocarcinoma. Although we accept that there may have been a potential bias in deciding which patients stayed at The Middlesex Hospital for radiotheraphy, we feel this unlikely as decisions were taken on geographical area of residence only.

It has previously been shown that survival is usually better in type I than type II/III cholangiocarcinomas, ${ }^{12}$ but in this study patients with advanced II/III strictures who were medically unfit were not included. The similarity in survival in those with a type I stricture may be due to the small numbers involved and no conclusions can usefully be drawn over the use of radiotherapy in this group from our study. In those with a type II/III cholangiocarcinoma there was a survival advantage in the 10 months after diagnosis. We believe there are several factors for this beneficial effect. In comparing the overall survival data with that pertaining only to the type II/III stricture group (Figs 1 and 2) the survival curves for the control groups are similar but those of the radiotherapy groups show a tendency for improved survival in the II/III stricture group in the first 10 months. We hypothesise that the radiotherapy serves to open up more biliary passages and that this effect is more obvious in a type II/III cholangiocarcinoma, where there is more small duct involvement and a greater incidence of segmental sepsis than in a type I cholangiocarcinoma. This effect, though, is relatively short lived and thereafter the radiotherapy does 
not seem to be of benefit, as is shown by the similarity of the survival curves in Figure 2 after 10 months, and also by the numbers surviving longer than one year (Table III). In addition, it cannot be denied that those patients receiving radiotherapy spent longer in hospital and therefore will have received better medical care and prompter intervention for any ensuing complications, and they also had more stent changes. All of these factors may well have had an impact on length of survival. It could, therefore, be argued that the apparent survival advantage in the radiotherapy group may be attributable more to the better care received than to the radiotherapy itself.

Patients receiving radiotherapy required more stent changes, although many of these will have been carried out at the same time of inserting the iridium-192 wire, as it seemed sensible to insert a catheter into a new and not partially blocked stent, and hence this may not necessarily reflect a greater stent failure rate. The length of hospital stay over the course of the illness was very much longer in those receiving radiotherapy, and this was mainly attributable directly to the administration of the radiotherapy itself and the higher incidence of stent changes. It must, of course, be borne in mind that the radiotherapy could be administered as an outpatient if geographically appropriate, and this would minimise hospital admissions and keep costs down.

The current cost of external beam and internal radiotherapy in the $\mathrm{UK}$ is $£ 1850$ per patient. If this is added to the cost of the hospital stay and of the endoscopic procedures, radiotherapy is a very expensive form of treatment. Even if given as an outpatient radiotherapy would still be a more expensive option than stenting alone. Overall the probable benefit of radiotherapy in the survival of patients with cholangiocarcinoma is only short lived and with patients spending a greater proportion of their remaining days in hospital it would seem difficult to justify, on the basis of current evidence, the routine use of radiotherapy in the treatment of unresectable cholangiocarcinoma. As a result of this study it would seem necessary to attempt a prospective randomised controlled trial that examines not only the effects of radiotherapy but also the quality of patient care and their quality of life. It may also be necessary to examine the additional effects of adding chemotherapy to the radiotherapy in an attempt to improve matters further. It may, however, be difficult to recruit patients into the stenting only group due to increasing patient expectation of active treatment.

1 Klatskin G. Adenocarcinoma of the hepatic duct at its bifurcation within the porta hepatis: an unusual tumour with distinctive clinical and pathological features. $A m \mathcal{F}$ Med 1965; 38: 241-56

2 Bismuth $H$, Nakache $R$, Diamond $T$. Management strategies in resection for hilar cholangiocarcinoma. Ann Surg 1992; 215: 31-8

3 Inoue AA, Whelan TJ. Carcinoma of the extrahepatic bile ducts: a ten year experience in Hawaii. Am $\mathcal{F}$ Surg 1978; 136: $90-5$.

4 Blumgart LH, Hadjis NS, Benjamin IS, Beazley R. Surgical approaches to cholangiocarcinoma at confluence of hepatic ducts. Lancet 1984; i: 66-70.

5 Langer JC, Langer B, Taylor BR, et al. Carcinoma of the extrahepatic bile ducts: results of an aggressive surgical approach. Surgery 1985; 98: 752-9.
6 Bismuth $\mathrm{H}$, Castaing $\mathrm{D}$, Traynor O. Resection or palliation: priority of surgery in the treatment of hilar cancer. World priority of surgery in the

7 Wheeler PG, Dawson JL, Nunnerley H, Brinkley D, Laws J. Newer techniques in the diagnosis and treatment of proximal bile duct carcinoma - an analysis of 41 consecutive patients. $Q \mathcal{F}$ Med 1981 ; 50: 247-59.

8 Broe PJ, Cameron JL. The management of proximal biliary tract tumours. Adv Surg 1981; 15: 47-61.

9 Fortner JG, Vitelli CE, Maclean BJ. Proximal extrahepatic bile duct tumours: analysis of a series of 52 consecutive patients treated over a period of 13 years. Arch Surg 1989; 124: 1275-9.

10 Ottow RT, August DA, Sugarbaker PH. Treatment of proximal biliary tract carcinoma: an overview of technique proximal biliary tract carcinoma: an overv

11 Alexander F, Rossi RI, O'Bryan M, et al. Biliary carcinoma: a review of 109 cases. Am $\mathcal{F}$ Surg 1984; 147: 503-9.

12 Polydorou AA, Cairns SR, Dowsett JF, Hatfield ARW, Salmon PR, Cotton PB, et al. Palliation of proximal malignant biliary obstruction by endoscopic endoprosthesis insertion. Gut 1991; 32: 685-9.

13 Fields JN, Emami B. Carcinoma of the extrahepatic biliary system: results of primary and adjuvant radiotherapy. Int f Radiat Oncol Biol Phys 1987; 13: 331-4.

14 Gibson RN, Yeung E, Hadjis NS, et al. Percutaneous transhepatic endoprostheses for hilar cholangiocarcinoma. Am f Surg 1988; 156: 363-7.

15 Hadjis NS, Adam A, Gibson R, et al. Nonoperative approach to hilar cancer determined by the atrophyapproach to hilar cancer determined by the atroph
hypertrophy complex. Am $\mathcal{F}$ Surg $1989 ; 157: 395-9$.

16 Hayes JK, Sapozink MD, Miller FJ. Definitive radiation therapy in bile duct carcinoma. Int $\mathcal{F}$ Radiat Oncol Biol Phys 1988; 15: 735-9.

17 Pilepich MV, Lambert RM. Radiotherapy of carcinomas of the extrahepatic biliary system. Radiology 1978; 127: 767-70.

18 Ohnishi $\mathrm{H}$, Asada M, Shichijo Y, Iijima N, Itobayashi E, Shimura $\mathrm{K}$, et al. External radiotherapy for biliary decompression of hilar cholangiocarcinoma Hepatogastroenterology 1995; 42: 265-268.

19 Busse PM, Stone MD, Sheldon TA, et al. Intraoperative radiation therapy for biliary tract carcinoma: results of a 5-year experience. Surgery 1989; 105: 724-8.

20 Iwasaki Y, Todoroki T, Fukao K, et al. The role of intraoperative radiation therapy in the treatment of bile

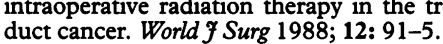

21 Todoroki T, Iwasaki Y, Okamura T, Nagoshi K, Asakura $\mathrm{H}$, Nakano $\mathrm{M}$, et al. Intraoperative radiotherapy for advanced carcinoma of the biliary system. Cancer 1980; 46: 2179-84.

22 Ede RJ, Williams SJ, Hatfield ARW, McIntyre S, Mair G. Endoscopic management of inoperable cholangio-

23 Koyama K, Tanaka J, Sato S, et al. New strategy for treatment of carcinoma of the hilar bile duct. Surg Gynaecol Obstet 1989; 168: 523-36.

24 Meyers WC, Jones RS. Internal radiation for bile duct cancer. World f Surg 1988; 12: 99-103.

25 Karani J, Fletcher M, Brinkley D, Dawson JL, Williams R, Nunnerley $H$. Internal biliary drainage and local radiotherapy with iridium-192 wire in treatment of hila cholangiocarcinoma. Clin Radiol 1985; 36: 603-6.

26 Levitt MD, Laurence BH, Cameron F, Klemp PFB Transpapillary iridium-192 wire in the treatment of malignant bile duct obstruction. Gut 1988; 29: 149-52.

27 Murray PA, Loke R, Crellin A, Craig P, Tapper PD, Loverock LT, et al. The treatment of cholangiocarcinoma with endoscopic decompression and iridium-192 brachytherapy. Br $₹$ Cancer 1991; 64: P57.

28 Fletcher MS, Brinkley D, Dawson JL, et al. Treatment of hilar carcinoma by bile drainage combined with internal radiotherapy using iridium-192 wire. Br $f$ Surg $1983 ; 70$. radiotherat

29 Fletcher MS, Dawson JL, Wheeler PG, Brinkley D, Nunnerley $H$, Williams $R$. Treatment of high bile duct carcinoma by internal radiotherapy with iridium-192 wire. Lancet 1981; ii: 172-4.

30 Herskovic A, Heaston D, Engler MJ, Fishburn RI Jones RS, Noell KT. Irradiation of biliary carcinoma. Radiology 1981; 139: 219-22.

31 Mornex F, Gerard JP, Bret P, Partensky C. Iridium wire radiotherapy for high bile duct carcinoma. Lancet 1981; ii: $479-81$.

32 Conroy RM, Shahbazian AA, Edwards KC, et al. A new method for treating carcinomatous biliary obstruction method for treating carcinomatous biliary obstructic

33 Molt P, Hopfan S, Watson RC, Botet JF, Brennan MF Intraluminal radiation therapy in the management of malignant biliary obstruction. Cancer $1986 ; 57: 536-44$.

34 Chitwood WR, Meyers WC, Heaston DK, Herskowic AM McLeod ME, Jones RS. Diagnosis and treatment of primary extrahepatic bile duct tumours. Am $\mathcal{F}$ Surg 1982; 143: $99-105$

35 Johnson DW, Safai C, Goffinet DR. Malignant obstructive jaundice: treatment with external beam and intracavitary radiotherapy. Int $\mathcal{F}$ Radiat Oncol Bio Phys 1985; 11 : 411-6.

36 Kuvshinoff BW, Armstrong JG, Fong Y, Schupak K, Getradjman G, Heffernan N, et al. Palliation or irresectable hilar cholangiocarcinoma with biliary drainage and radiotherapy. Br F Surg 1995; 82: 1522-5.

37 Tsujino K, Landry KC, Smith RG, Keller JW, Williams WH, Davis LW. Definitive radiation therapy fo 275-80. 